\title{
Potential refugia in Taiwan revealed by the phylogeographical study of Castanopsis carlesii Hayata (Fagaceae)
}

\author{
YU-PIN CHENG ${ }^{*} \ddagger$ SHIH-YING HW ANG + and TSAN-PIAO LIN * \\ *Institute of Plant Biology, National Taiwan University, Taipei 106, Taiwan, +Graduate Institute of Biotechnology, Chinese Culture \\ University, Yangmingshan, Taipei 111, Taiwan, $\ddagger$ Division of Forest Biology, Taiwan Forestry Research Institute, Taipei 100, Taiwan
}

\begin{abstract}
In this study, we examined spatial patterns of chloroplast DNA (cpDNA) variation in a total of 30 populations of Castanopsis carlesii Hayata (Fagaceae), a subtropical and temperate tree species, including 201 individuals sampled throughout Taiwan. By sequencing two cpDNA fragments using universal primers (the $t r n \mathrm{~L}$ intron and the $t r n \mathrm{~V}$-trnM intergenic spacer), we found a total of $1663 \mathrm{bp}$ and 21 polymorphic sites. These gave rise to a total of 28 cpDNA haplotypes. The level of differentiation among the populations studied was relatively high $\left(G_{\mathrm{ST}}=0.723\right)$. Two ancestral haplotypes are widely distributed. The Central Mountain Ridge (CMR) of Taiwan represents an insurmountable barrier to the east-west gene flow of $C$. carlesii. Among the populations studied, three separated populations, at Lienhuachih, Fushan and Lichia, have high nucleotide diversity. Estimates of $N_{\mathrm{ST}}-G_{\mathrm{ST}}$ for populations on both sides of the CMR indicate that no phylogeographical structure exists. According to the genealogical tree, number of rare haplotype and population genetic divergence, this study suggests that two potential refugia existed during the last glaciation: the first refugium was located in a region to the north of Hsuehshan Range (HR) and west of the CMR; the second refugium was located in south, especially southeastern Taiwan. In fact, the second refugium happens to be the same as that reported for Quercus glauca. A 'star-like' genealogy is characteristic when all haplotypes rapidly coalesce and is a general outcome of population expansion. The neutrality test and mismatch distribution also suggest demographic expansion recovering from a bottleneck.
\end{abstract}

Keywords: Castanopsis carlesii Hayata, cpDNA, phylogeography, refugium, Taiwan

Received 1 January 2005; revision accepted 1 March 2005

\section{Introduction}

Cyclical migrations during glacial events of the Pleistocene have had profound influences on population genetic structures as a result of restrictions in some specific regions and subsequent migration by seed dispersal during interglacial periods (Hewitt 2000). At low latitudes, a situation existed as in temperate regions but was probably less extensive, and species replacement and migration also left their mark in the fossil pollen record (Tsukada 1966, 1967). Nevertheless, species with different ecological requirements

Correspondence: Dr Tsan-Piao Lin, National Taiwan University, Institute of Plant Biology, Roosevelt Road, Section 4, Taipei, Taiwan 106; Fax: 886-2-2368-9564; E-mail: tpl@ntu.edu.tw and distributions, may have led to dissimilarities in refugia and migration routes (Taberlet et al. 1998). Thus, the present status of distribution represents the effects of various geographical barriers (Demesure et al. 1996; Taberlet et al. 1998; Hiramatsu et al. 2001), dispersal behaviours and abilities (Richardson et al. 2002), and colonization competition (Petit et al. 1997; Brewer et al. 2002), with resultant nonsynchronous migration. The study of many species with different ecological requirements is needed to evaluate the similar/ dissimilar evolutionary responses.

Taiwan as a continental island has high levels of endemism and species diversity in its floristic composition. Most flora was thought to have originated from the Asian mainland during cycles of temperature oscillations. The geological evidence indicates that ice ages have occurred at regular 
intervals of approximately 100000 years followed by 20000 years of warmer periods (Milankovitch cycles) (Bennett 1990). Although the land in Taiwan has never been covered by ice sheets, the tremendous temperature and climatic changes should have influenced species' distributions and evolution. During glacial expansions, most subtropical species would have retreated into more southerly or warmer lowland areas, namely refugia. At the same time, temperate species would have expanded their range of distribution from high elevations, and lowland forests might have been dominated by conifers (Tsukada 1967). When the ice retreated, a reverse course of events occurred with subtropical species recolonizing from south to north, and lowland forests colonizing higher elevations. The current geographical distribution of living organisms is the result of both present and past ecological or historical factors. The last glacial age might have been an important factor in shaping the genetic structure and phylogeographical patterns of plant species in Taiwan. Elucidating the evolutionary history of species in Taiwan is interesting to biological evolutionists.

Molecular techniques, using organelle markers, have provided tools for studying the phylogeography or migratory footprints of species (Avise 2000). In plants, chloroplast DNA (cpDNA) is thought to evolve slowly, with low mutation (Wolfe et al. 1987; Li 1997) and recombination rates (Clegg \& Zurawski 1992), and thus it is a good tool to study genetic variation of closely related species or at the intraspecific level, particular of noncoding regions. Chloroplast DNA is known to be maternally inherited in most angiosperms, and thus gene flow or haplotype exchange occurs exclusively by seeds (Corriveau \& Coleman 1988).
Maternally inherited markers generally reveal much greater genetic structure than nuclear markers, and have a smaller effective population size than nuclear DNA (Petit et al. 1993; Hare 2001). So, cpDNA markers are useful tools in the study of phylogeography for discussing spatiotemporal dynamics of plant species and for identifying postglacial colonization routes (Dumolin-Lapegue et al. 1997; Ferris et al. 1998; Matyas \& Sperisen 2001; Csaikl et al. 2002).

According to the highest expected heterozygosities based on allozyme data of many species, a primary diversity centre has been proposed to have existed in Nantou County, central Taiwan and west of the Central Mountain Ridge (CMR) (Lin 2001; Fig. 1). These species include Myrica rubra (Lour.) Sieb. \& Zucc., Cinnamomum kanehirae Hay., Cunninghamia konishii Hay., Trochodendron aralioides Sieb. \& Zucc., and Michelia compressa (Max.) Sargent. According to cpDNA polymorphism and nucleotide diversity, Huang et al. (2002) proposed that the southeastern part of Taiwan might have been a potential refugium for Cyclobalanopsis glauca, a widespread subtropical species in Taiwan. Huang et al. (2004) however, after studying T. aralioides, a temperate species, inferred that the north-central region, west of the CMR was its potential refugium during the last glaciation. Different evolutionary histories and adaptive potentials should lead to different phylogeographical patterns between subtropical and temperate species and likely caused these contradictory results.

Castanopsis carlesii Hayata, belonging to the Fagaceae, is an evergreen tree species. It generally occurs in forests at median to high elevations throughout the island of Taiwan,

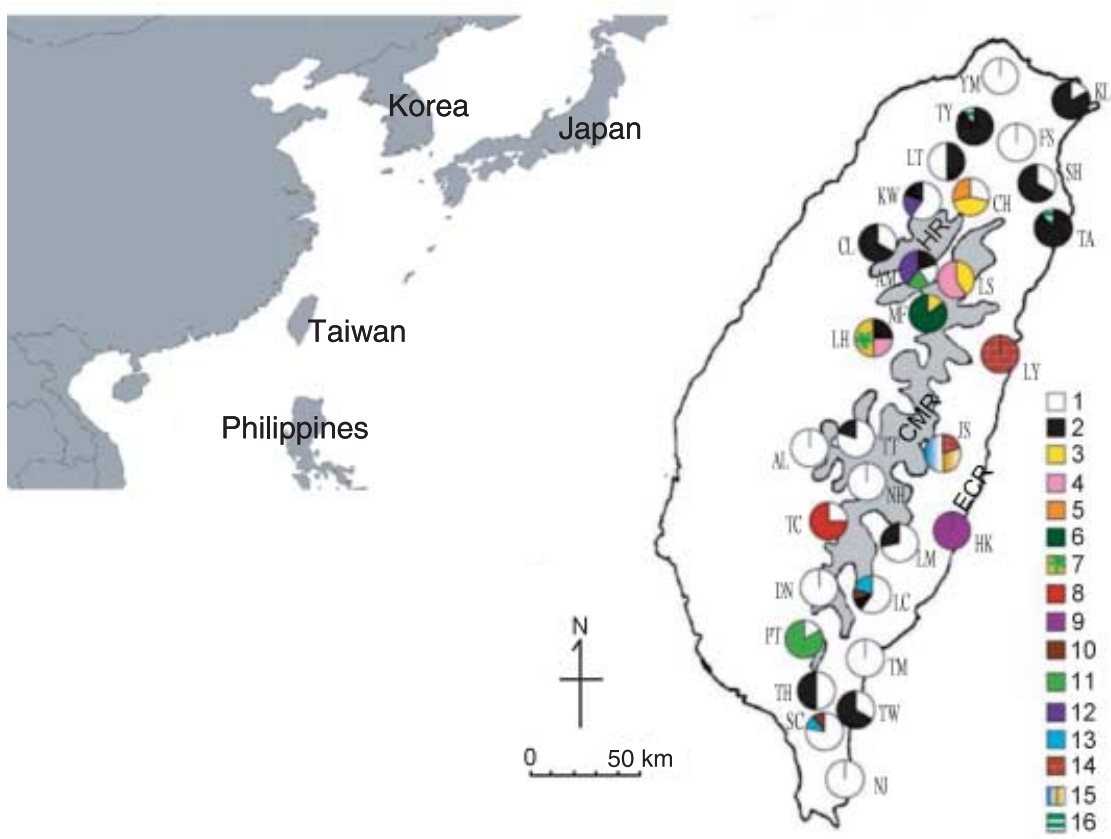

Fig. 1 Map of East Asia and Taiwan and the geographical distribution of cpDNA haplotypes of Castanopsis carlesii. Only the 16 haplotypes that occurred in more than two individuals are shown. CMR, Central Mountain Ridge; HR, Hsuehshan Range; ECR, East Coastal Range. 
and has a vertical distribution ranging from 1000 to $2300 \mathrm{~m}$, but descends to low elevations on both the northern and southern sides of the island. Thus $C$. carlesii has adapted to a wide range of ecological habitats. Castanopsis carlesii is one of the most important and dominant species of the Machilus-Castanopsis forest and evergreen oak forests in Taiwan (Hsieh et al. 1994; Shen 1994). Due to limited uses of its wood, no man-made plantation was ever established. For slight morphological variations, such as differences in the colour on the underside of the leaves and leaf morphology, this species had been identified into two forms, C. cuspidata var. carlesii f. carlesii and C. cuspidata var. carlesii f. sessilis (Liao 1996). However, according to field observations, morphological variation may represent developmental plasticity in response to environmental stimuli and no clear boundary can be drawn between these two formas. Most Fagaceae species have large, weighted seeds, and dispersal of seeds is mostly by means of gravity. The reason we selected this species for phylogeographical study is because the distributional range of $C$. carlesii corresponds to that of T. aralioides and C. glauca, and this allows us to investigate the relationships of colonization patterns and the possible refugia among these species.

In this study, we estimated parameters of diversity of cpDNA in C. carlesii to infer the possible glacial refugia in Taiwan. We also investigated the geographical distribution of cpDNA haplotypes in 30 populations of $C$. carlesii, and used the information to discuss the postglacial history of this species, including the geographical effect of the CMR on gene flow and population expansion.

\section{Materials and methods}

Sampling

In total, 30 populations of Castanopsis carlesii, including 201 individuals, were sampled throughout Taiwan (Table 1; Fig. 1). Sample sizes of each population ranged from 3 to 11

Table 1 Population numbers, sample sizes, altitude, location, estimates of haplotype diversity $(h)$, nucleotide diversity $\left(\pi \times 10^{3}\right)$ and haplotypes of Castanopsis carlesii sampled in this study

\begin{tabular}{|c|c|c|c|c|c|c|c|c|}
\hline Populations & $\begin{array}{l}\text { Sample } \\
\text { sizes }\end{array}$ & Location & $\begin{array}{l}\text { Altitude } \\
(\mathrm{m})\end{array}$ & $\begin{array}{l}\text { No. of } \\
\text { haplotype }\end{array}$ & $\begin{array}{l}\text { Polymorphic } \\
\text { sites }\end{array}$ & $h$ & $\pi \times 10^{3}$ & $\begin{array}{l}\text { Haplotypes } \\
\text { (no. of individuals) }\end{array}$ \\
\hline Total & 201 & & & 28 & 26 & 0.761 & 0.95 & \\
\hline 1. Yangmingshan (YM) & 8 & $121.50^{\circ} \mathrm{E}, 25.18^{\circ} \mathrm{N}$ & 400 & 1 & 0 & 0.000 & 0.00 & $1(8)$ \\
\hline 2. Kungliao (KL) & 6 & $121.93^{\circ} \mathrm{E}, 25.02^{\circ} \mathrm{N}$ & 100 & 2 & 1 & 0.333 & 0.20 & $1(1), 2(5)$ \\
\hline 3. Fushan (FS) & 6 & $121.60^{\circ} \mathrm{E}, 24.77^{\circ} \mathrm{N}$ & 600 & 4 & 5 & 0.800 & 1.16 & $1(3), 17(1), 18(1), 19$ (1) \\
\hline 4. Tungyenshan (TY) & 10 & $121.40^{\circ} \mathrm{E}, 24.83^{\circ} \mathrm{N}$ & 800 & 2 & 1 & 0.200 & 0.12 & $2(9), 16(1)$ \\
\hline 5. Tungao (TA) & 9 & $121.83^{\circ} \mathrm{E}, 24.48^{\circ} \mathrm{N}$ & 600 & 2 & 1 & 0.222 & 0.13 & $2(8), 16(1)$ \\
\hline 6. Sanhsing (SH) & 6 & $121.57^{\circ} \mathrm{E}, 24.82^{\circ} \mathrm{N}$ & 500 & 2 & 1 & 0.533 & 0.48 & $1(2), 2(4)$ \\
\hline 7. Kuanwu (KW) & 5 & $121.12^{\circ} \mathrm{E}, 24.50^{\circ} \mathrm{N}$ & 2000 & 3 & 2 & 0.700 & 0.48 & $1(3), 2(1), 12(1)$ \\
\hline 8. Chenghsipao $(\mathrm{CH})$ & 7 & $121.23^{\circ} \mathrm{E}, 24.55^{\circ} \mathrm{N}$ & 1500 & 3 & 2 & 0.762 & 0.57 & $1(2), 3(3), 5(2)$ \\
\hline 9. Litungshan (LT) & 6 & $121.30^{\circ} \mathrm{E}, 24.70^{\circ} \mathrm{N}$ & 1300 & 2 & 1 & 0.600 & 0.36 & $1(3), 2(3)$ \\
\hline 10. Chialishan (CL) & 3 & $121.02^{\circ} \mathrm{E}, 24.52^{\circ} \mathrm{N}$ & 1500 & 2 & 1 & 0.677 & 0.40 & $1(1), 2(2)$ \\
\hline 11. Anmashan (AM) & 5 & $120.97^{\circ} \mathrm{E}, 24.25^{\circ} \mathrm{N}$ & 2000 & 4 & 3 & 0.900 & 0.84 & $1(1), 2(1), 11(1), 12(2)$ \\
\hline 12. Lishan (LS) & 5 & $121.27^{\circ} \mathrm{E}, 24.22^{\circ} \mathrm{N}$ & 2200 & 2 & 1 & 0.600 & 0.36 & $3(2), 4(3)$ \\
\hline 13. Liyushan (LY) & 8 & $121.52^{\circ} \mathrm{E}, 23.93^{\circ} \mathrm{N}$ & 500 & 2 & 2 & 0.500 & 0.30 & $14(7), 20(1)$ \\
\hline 14. Juisui (JS) & 4 & $121.28^{\circ} \mathrm{E}, 23.50^{\circ} \mathrm{N}$ & 1400 & 2 & 1 & 0.400 & 0.24 & $14(1), 15(4)$ \\
\hline 15. Meifeng (MF) & 8 & $121.17^{\circ} \mathrm{E}, 24.10^{\circ} \mathrm{N}$ & 2000 & 3 & 3 & 0.464 & 0.45 & $3(1), 6(6), 28(1)$ \\
\hline 16. Lienhuachih (LH) & 6 & $120.88^{\circ} \mathrm{E}, 23.92^{\circ} \mathrm{N}$ & 700 & 5 & 4 & 0.933 & 1.36 & $2(1), 4(1), 7(2), 25(1), 26(1)$ \\
\hline 17. Tataka (TT) & 5 & $120.87^{\circ} \mathrm{E}, 23.48^{\circ} \mathrm{N}$ & 2200 & 2 & 1 & 0.400 & 0.24 & $1(4), 2(1)$ \\
\hline 18. Alishan (AL) & 6 & $120.78^{\circ} \mathrm{E}, 23.50^{\circ} \mathrm{N}$ & 1700 & 1 & 0 & 0.000 & 0.00 & $1(6)$ \\
\hline 19. Tengchih (TC) & 7 & $120.75^{\circ} \mathrm{E}, 23.07^{\circ} \mathrm{N}$ & 1400 & 5 & 4 & 0.857 & 0.69 & $1(1), 8(3), 21(1), 22(1), 27(1)$ \\
\hline 20. Nanheng (NH) & 11 & $120.92^{\circ} \mathrm{E}, 23.28^{\circ} \mathrm{N}$ & 2200 & 1 & 0 & 0.000 & 0.00 & $1(11)$ \\
\hline 21. Tona (TN) & 5 & $120.73^{\circ} \mathrm{E}, 22.92^{\circ} \mathrm{N}$ & 1000 & 1 & 0 & 0.000 & 0.00 & $1(5)$ \\
\hline 22. Peitawu (PT) & 6 & $120.73^{\circ} \mathrm{E}, 22.58^{\circ} \mathrm{N}$ & 1500 & 2 & 1 & 0.333 & 0.20 & $1(1), 11(5)$ \\
\hline 23. Tahanshan (TH) & 6 & $120.75^{\circ} \mathrm{E}, 22.42^{\circ} \mathrm{N}$ & 1200 & 2 & 1 & 0.600 & 0.36 & $1(3), 2(3)$ \\
\hline 24. Shouchia (SC) & 9 & $120.83^{\circ} \mathrm{E}, 22.25^{\circ} \mathrm{N}$ & 500 & 3 & 3 & 0.470 & 0.40 & $1(7), 10(1), 13(1)$ \\
\hline 25.Nanjenshan (NJ) & 6 & $120.85^{\circ} \mathrm{E}, 22.07^{\circ} \mathrm{N}$ & 400 & 1 & 0 & 0.000 & 0.00 & $1(6)$ \\
\hline 26. Hsinkangshan (HK) & 6 & $121.32^{\circ} \mathrm{E}, 23.13^{\circ} \mathrm{N}$ & 1200 & 1 & 0 & 0.000 & 0.00 & $9(6)$ \\
\hline 27. Lumingshan (LM) & 9 & $121.07^{\circ} \mathrm{E}, 22.93^{\circ} \mathrm{N}$ & 1100 & 4 & 3 & 0.694 & 0.50 & $1(5), 2(2), 23(1), 24(1)$ \\
\hline 28. Lichia (LC) & 10 & $120.98^{\circ} \mathrm{E}, 22.83^{\circ} \mathrm{N}$ & 1200 & 4 & 6 & 0.644 & 0.91 & $1(6), 9(1), 10(1), 13(2)$ \\
\hline 29. Tawu (TW) & 6 & $120.97^{\circ} \mathrm{E}, 22.38^{\circ} \mathrm{N}$ & 400 & 2 & 1 & 0.533 & 0.32 & $1(2), 2(4)$ \\
\hline 30. Taimali (TM) & 6 & $120.97^{\circ} \mathrm{E}, 22.63^{\circ} \mathrm{N}$ & 700 & 1 & 0 & 0.000 & 0.00 & $1(6)$ \\
\hline
\end{tabular}


individuals. Young, developed leaves were collected from the field and preserved on ice or dried with silica gel, then immediately carried back to the laboratory at the Taiwan Forestry Research Institute. All examined samples were deposited at the Herbarium of Taiwan Forestry Research Institute (TAIF), Taipei.

\section{Polymerase chain reaction (PCR) and sequencing}

Leaf tissue of $C$. carlesii was powdered in liquid nitrogen and stored at $-70{ }^{\circ} \mathrm{C}$ until used. Total genomic DNA was extracted from ground leaf powder using a Viogene plant genomic DNA mini prep system kit. The concentration and quality of extracted DNA were checked by $1 \%$ agarose gel electrophoresis with a Lambda/HindIII/EcoRI marker. Polymerase chain reaction (PCR) was used to isolate and amplify the noncoding region of $\mathrm{cpDNA}$, and two fragments were used for analysis in this study: the $t r n \mathrm{~L}$ intron (5'-TGGATTGAGCCTTGGTATGG-3' and 5'-TCTACCAGCTGAGCTATCCC-3') and trnV-trnM (5'-GCTATACGGGCTCGAACC-3' and 5'-TACCTACTATTGGATTTGAACC-3'). PCR was conducted on an OMN-E Thermal Cycler (Thermo Hybaid), and performed with initial denaturing of $5 \mathrm{~min}$ at $95^{\circ} \mathrm{C}$ followed by 40 cycles of $1 \mathrm{~min}$ at $94{ }^{\circ} \mathrm{C}, 1 \mathrm{~min}$ of annealing at $52{ }^{\circ} \mathrm{C}$ for the $\operatorname{trn} \mathrm{L}$ intron and $62^{\circ} \mathrm{C}$ for the trn $\mathrm{V}$-trn $\mathrm{M}, 1 \mathrm{~min}$ of elongation at $72{ }^{\circ} \mathrm{C}$, ending with a 10 -min extension at $72{ }^{\circ} \mathrm{C}$. The PCR products were checked on a $1 \%$ agarose gel, then PCR products with a single band were directly sequenced in both directions by standard methods using a Taq dye deoxy terminator cycle sequencing kit on an Applied Biosystems Model 377 automated sequencer (Applied Biosystems).

\section{Sequence alignment and phylogenetic analysis}

DNA sequencing was analysed using Data Analysis in Molecular Biology and Evolution (DAMBE, Xia \& Xie 2001). Multiple alignments of the sequences were obtained using CLUSTAL w (Thompson et al. 1994). The haplotype diversity $(h)$ and nucleotide diversity $(\pi)$ were calculated with the program DNA sequence polymorphism (DNASP version 3.53, Rozas \& Rozas 1999). Tests of the neutrality, Taijima's $D$ and $\mathrm{Fu} \& \mathrm{Li}^{\prime} \mathrm{s} D^{*}$ and $F$, and the determination of their associated significance were also conducted, and a pairwise mismatch distribution was used to test for population expansion (Rogers \& Harpending 1992) with this program. In this study, fragments of insertion or deletion (indels) in sequences were treated as a single mutation event. The program Tcs version 1.06 was used to construct the phylogenetic network of haplotypes (Templeton et al. 1992). The distance matrix among populations was constructed with MEGA version 2.1 (Kumar et al. 2001) calculated with the Kimura 2-parameter method (Kimura 1980).

\section{Analysis of population structure}

Two measures of diversity and population differentiation were analysed with the HAPSTEP program (version 2001, http://www.pierroton.inra.fr/genetics/labo/software) as described in Pons \& Petit $(1995,1996)$. The parameters include the mean within-population gene diversity $\left(H_{\mathrm{S}}\right)$, the total gene diversity $\left(H_{\mathrm{T}}\right)$, and the coefficient of genetic differentiation over all populations $\left(G_{\mathrm{ST}}\right)$, as well as the other equivalent parameters $\left(V_{\mathrm{S}}, V_{\mathrm{T}}\right.$ and $\left.N_{\mathrm{ST}}\right)$ obtained by taking into account similarities between haplotypes. $G_{\mathrm{ST}}$ depends only on the frequencies of the haplotypes. However, $N_{\mathrm{ST}}$ is influenced by both haplotype frequencies and the distances between haplotypes. Conventional $F_{\mathrm{ST}}$ (Wright 1931) based on cpDNA sequences for population subdivision was estimated using an analysis of molecular variance (AMOVA) implemented using the program ARLEQUIN (Schneider et al. 2000). In addition, the level of divergence for each population from the remaining populations was calculated as mean values of pairwise $F_{\mathrm{ST}}$ of the populations against the rest of populations. The contribution to total diversity $(C T)$ and total allelic richness (CTR) of each population were calculated according to Petit et al. (1998), using the CONTRIB software (version 1999, http//http://www. pierroton.inra.fr/genetics/labo/software). Two components of the total contribution of a population to diversity, withinpopulation diversity (CS and CSR) and its differentiation $(C D$ and $C D R$ ), were also estimated for the total diversity and allelic richness, respectively.

\section{Results}

\section{Chloroplast DNA polymorphism and genetic diversity}

The examined sequences consisted of $\operatorname{trn} \mathrm{L}$ intron (801 bp, GenBank Accession nos AY714626-AY714646) and trnVtrn $\mathrm{M}$ intergenic spacer (862 bp, GenBank Accession nos AY714620-AY714625). Sequence lengths varied from $1646 \mathrm{bp}$ to $1662 \mathrm{bp}$, with a consensus length of $1663 \mathrm{bp}$. In total, 26 polymorphic sites (1.5\%), with 17 informative sites, were detected within these two intergenic spacers. Among them, 21 polymorphic sites $(2.6 \%)$ were detected in the $\operatorname{tr} \mathrm{L}$ intron, and $5(0.6 \%)$ were detected in the trnV-trn M spacer. Among polymorphic sites, 18 were caused by point mutation, and 8 were the result of insertions or deletions (indels) that included two 6-bp and one 10-bp indels in the trn L intron.

The DNASP program was used to estimate the genetic diversity at population and species levels. Nucleotide diversity $(\pi)$ among the 30 populations ranged from 0 to 0.00136 , with an average of 0.00095 (Table 1). The LH population, located in central Taiwan, had the highest level of nucleotide diversity $(\pi=0.00136)$. Populations FS $(\pi=0.00116)$ in northern Taiwan and LC $(\pi=0.00091)$ in southeastern Taiwan also had high levels of nucleotide 
diversity. The genetic diversity of the $\operatorname{tr} n \mathrm{~L}$ intron (0.00148) was three times greater than that of the $t r n \mathrm{~V}-t r n \mathrm{M}$ spacer (0.00045) (data not shown). In the trn $\mathrm{V}$-trn $\mathrm{M}$ spacer, only four populations, MF, LH, TC and LC, were found to be variable.

\section{Haplotype polymorphism and distribution}

Twenty-eight cpDNA haplotypes (haplotypes 1-28) were identified from the 26 polymorphic sites of 201 sequences using the Tcs program (Table 2). The distributions and frequencies of these haplotypes are listed in Table 1 and Fig. 1. Among these 28 haplotypes, 16 haplotypes (1-16) each occurred in more than two individuals; the other 12 haplotypes (17-28) were singleton, only occurred in one individual, and were excluded from Fig. 1.

Haplotype diversities $(h)$ among the total of 30 populations ranged from 0 to 0.933 with an average of 0.761 . Population LH containing five haplotypes was the most variable population $(h=0.933)$. Other populations, such as
FS $(h=0.800), \mathrm{AM}(h=0.900), \mathrm{CH}(h=0.762)$ and TC $(h=$ 0.857), also contained high levels of haplotype diversity (Table 1). The haplotype diversity of two southeastern populations, LM and LC, was lower than the average value. However, these two close populations contained a total of seven different haplotypes.

From the TCs genealogical analysis (Fig. 2), haplotypes 1 (87 individuals) and 2 (44 individuals) were identified by one 6-bp indel difference in the $t r n \mathrm{~L}$ intron (290-295) (Table 2). These two haplotypes were widely distributed in most populations, except some populations of central Taiwan, such as LS, MF and east of the CMR, such as LY, JS and HK. Haplotype 3 was derived from type 1 due to a 10bp indel in the $t r n \mathrm{~L}$ intron (475-484), and five types $(4,5$, 6,7 and 28) were generated from this type. These six types were grouped into a clade restricted to the populations located in central to northern Taiwan, including LH, MF, LS and $\mathrm{CH}$. Type 23, also derived from type 1 due to a substitution in the trnL intron (469) was a singleton at LM, but

Table 2 Distribution of informative polymorphic sites in the noncoding spacers of cpDNA of Castanopsis carlesii. All allele sequences are compared to the reference allele from the haplotype 1 . The positions of the polymorphic sites in $\operatorname{trn} \mathrm{L}$ intron and $\operatorname{trn} \mathrm{V}$-trn $\mathrm{M}$ spacer, and deletion (-) are indicated

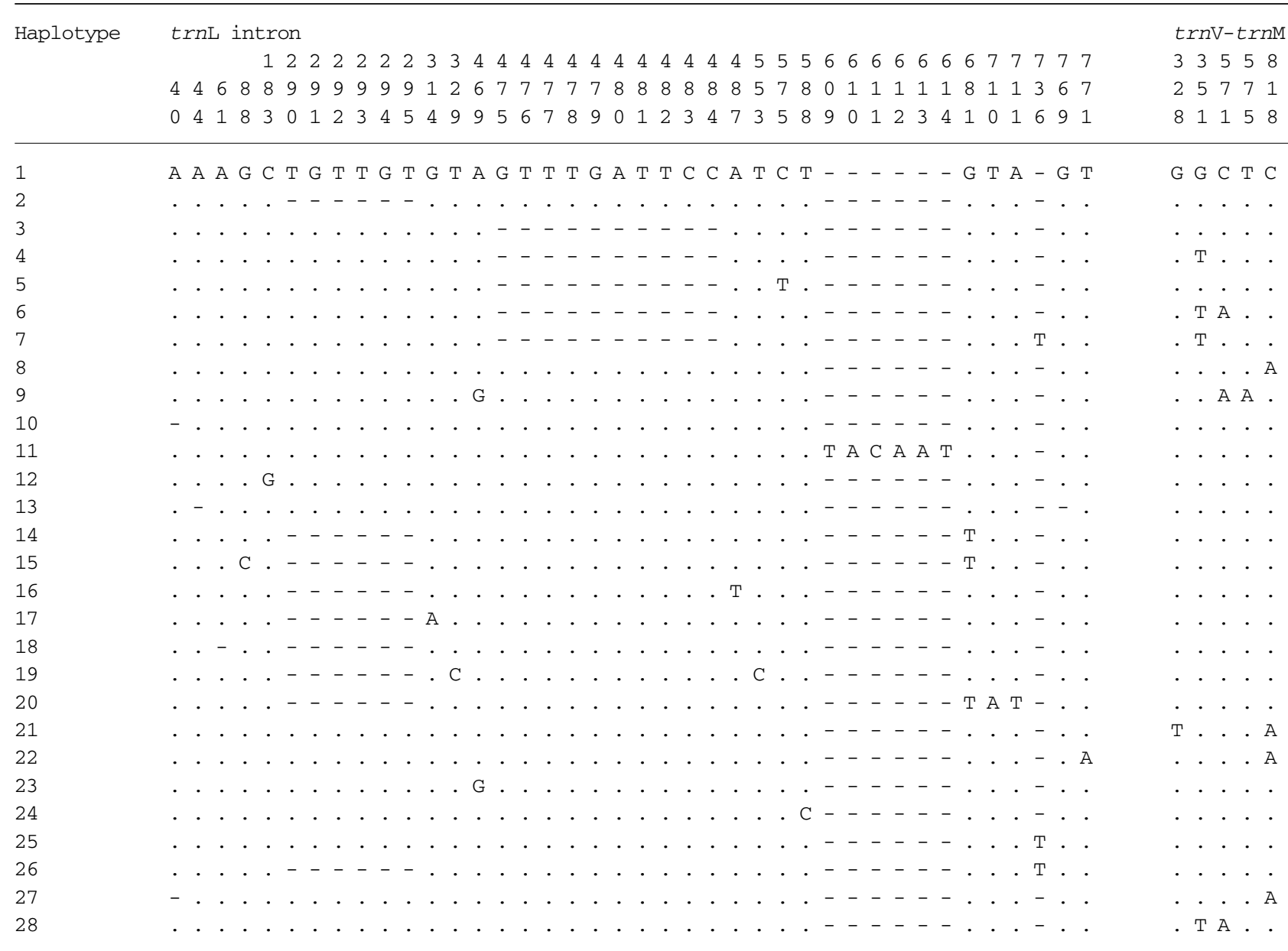




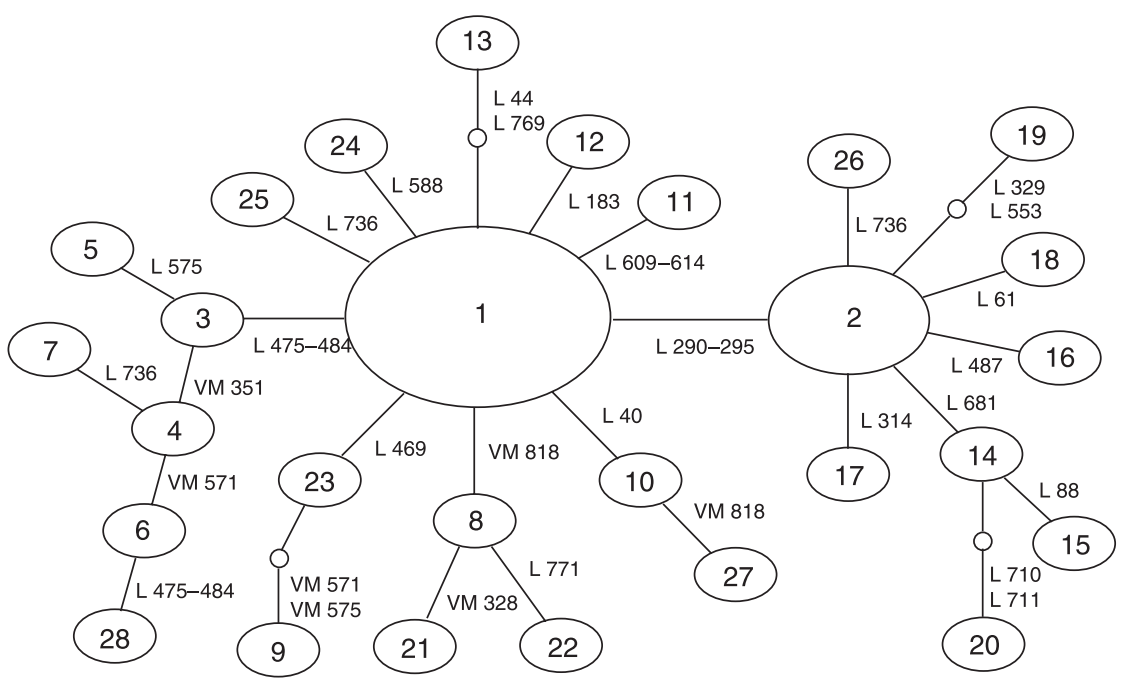

Fig. 2 The genealogical relationships between haplotypes of Castanopsis carlesii based on the $\operatorname{trn} \mathrm{L}$ intron and $t r n \mathrm{~V}$-trn $\mathrm{M}$ spacer of the cpDNA genome. Each line between haplotypes represented a mutational step, with numbers on lines indicating the variable base pair position.

Table 3 Population numbers, estimates of haplotype diversity $(h)$, nucleotide diversity $(\pi)$ and test statistics of neutrality of Castanopsis carlesii sampled in this study

\begin{tabular}{lllllllll}
\hline & $\begin{array}{l}\text { No. of } \\
\text { populations }\end{array}$ & $\begin{array}{l}\text { No. of } \\
\text { haplotypes }\end{array}$ & $\begin{array}{l}\text { No. of } \\
\text { polymorphic sites }\end{array}$ & $h$ & $\pi$ & $D$ & $D^{*}$ & $F^{*}$ \\
\hline Total & 30 & 28 & 26 & 0.761 & 0.00095 & $-1.79054^{*}$ & -1.96175 & -2.27687 \\
Western Taiwant & 19 & 20 & 17 & 0.761 & 0.00087 & -1.50225 & $-2.48941^{*}$ & $-2.53368^{*}$ \\
Eastern Taiwan $\ddagger$ & 11 & 11 & 12 & 0.750 & 0.00099 & -1.02965 & -0.76420 & -1.01878 \\
\hline
\end{tabular}

+Included populations 1, 2, 3, 4, 6, 7, 8, 9, 10, 11, 12, 15, 16, 17, 18, 19, 20, 21 and 22.

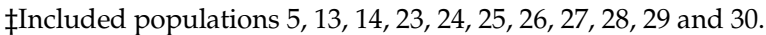

${ }^{*} P<0.05$.

this type producing type 9 was only found at LC (1) and HK (6). Types 23 and 9 were restricted to populations located in southeastern Taiwan. HK seated at the East Coastal Range (ECR, which is about $140 \mathrm{~km}$ long and $10 \mathrm{~km}$ wide; Fig. 1), was the only population in which all samples were type 9. The ECR is separated from the CMR by the narrow Taitung Valley plain which is only $3-6 \mathrm{~km}$ wide. Type 8 was derived from type 1 due to a substitution in the $t r n \mathrm{~V}-t r n \mathrm{M}$ spacer (818). Two different haplotypes (21 and 22) were produced from type 8 due to 1 base substitution. Types 8 , 21 and 22 were found only in population TC. Type 10 was also derived from type 1 and produced type 27 , that were found at LC, SC and TC. The other haplotypes derived from type 1 were almost singleton or located in restricted populations. Haplotype 14 was derived from type 2 and produced two types (15 and 20); these three types were found in LY and JS east of the CMR. The other types $(16,17,18,19$ and 26) derived from type 2 were due to 1- or 2-step site changes. These haplotypes were only found in northern Taiwan.

Morphological variations have been found among the samples. For example, the leaves of coastal area are thicker and rusty beneath while mountainous leaves showing silvery beneath mixed with rusty beneath. However, haplotypes found between them are not differentiated. These preliminary observations indicate that different forms of $C$. carlesii can not be separated by cpDNA sequence.

\section{Effect of the Central Mountain Range on haplotype distribution}

From the distribution of haplotypes (Fig. 1), it is easy to recognize that these haplotypes are not randomly distributed, but that some haplotypes were restricted to particular areas and showed geographical patterns of distribution. The CMR is a geographical barrier restricting gene flow or migration of haplotypes between western and eastern populations. Shen (1997) proposed that the flora of Taiwan could be divided into southeastern Taiwan floristic-superdistrict and northwestern Taiwan floristic-superdistrict. The boundary line between these two floristic-superdistricts begins at Tahanshan (south Taiwan) and proceeds northward along the east side of the CMR and ends at Chingshuishan, close to population TA (Fig. 1). According to Shen's idea, we divided the 30 populations into two groups, western (19 populations) and eastern (11 populations) and their respective haplotype diversities were 0.761 and 0.750 (Table 3). 
However, the nucleotide diversity east of the CMR (0.00099) was higher than that west of the CMR (0.00087).

The neutrality test by Tajima's $D(D=-1.79054, P<0.05)$ showed a negative value significantly different from 0 in all populations. When geographical groups were considered separately, the neutral test values of both were negative but insignificant (Table 3). To investigate the hypothesis of population expansion in C. carlesii, we computed the distribution of pairwise differences from segregation sites of cpDNA haplotypes using the DNASP program. Under a constant population model, the general distribution follows a gradually declining curve (Rogers \& Harpending 1992). The observed mismatch distribution departed from the expectation by showing a single main peak, and the raggedness statistics $r$, a measure of the smoothness of the distribution (Harpending 1994), was 0.0355, as expected for a population having experienced recent growth (Fig. 3), in contrast to a constant population model.

\section{Diversity and differentiation}

Estimates of diversity and differentiation were based on 30 populations and measured from frequencies of the haplotypes. A high proportion of detected variation resulted from differences among populations, $G_{\mathrm{ST}}=0.723$ (Table 4). $N_{\mathrm{ST}}$ is another parameter that can be used to investigate whether the geographical distributions of related haplotypes are clustered. The permutation test showed that $N_{\mathrm{ST}}$ was significantly higher than $G_{\mathrm{ST}}(P<0.05)$. If populations were divided into two geographical groups separated by the CMR, populations in eastern Taiwan $\left(G_{\mathrm{ST}}=0.835, H_{\mathrm{T}}=\right.$

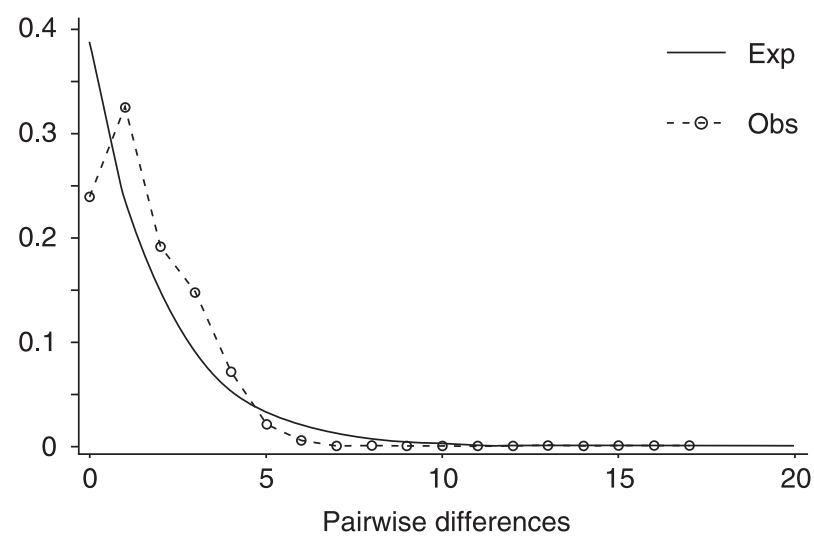

Fig. 3 Mismatch distribution established for Castanopsis carlesii. The thin line represents the expected mismatch distribution of a stationary population. The dotted line represents the observed mismatch distribution from segregation sites of the aligned sequences of the $\operatorname{trn} \mathrm{L}$ intron and $\operatorname{trn} \mathrm{V}-\operatorname{trn} \mathrm{M}$ intergenic spacers of cpDNA in Castanopsis carlesii. The raggedness statistics $r$, a measure of the smoothness of the distribution, was 0.0355 .
Table 4 Analysis of population substructure of Castanopsis carlesii in Taiwan

\begin{tabular}{llll}
\hline $\begin{array}{l}\text { Diversity } \\
\text { parameters }\end{array}$ & Total & West of CMR $\dagger$ & East of CMR \\
\hline$H_{\mathrm{S}}$ & $0.123(0.0403)$ & $0.147(0.0571)$ & $0.082(0.0495)$ \\
$H_{\mathrm{T}}$ & $0.444(0.0532)$ & $0.413(0.0637)$ & $0.496(0.0817)$ \\
$G_{\mathrm{ST}}$ & $0.723(\mathrm{NC})$ & $0.644(\mathrm{NC})$ & $0.835(0.0574)$ \\
$V_{\mathrm{S}}$ & $0.087(0.0307)$ & $0.104(0.0434)$ & $0.059(0.0382)$ \\
$V_{\mathrm{T}}$ & $0.379(0.0797)$ & $0.326(0.0788)$ & $0.450(0.1382)$ \\
$N_{\mathrm{ST}}$ & $0.770(0.0661)$ & $0.681(0.0630)$ & $0.870(0.0834)$ \\
$N_{\mathrm{ST}}-G_{\mathrm{ST}}$ & $0.047^{*}$ & 0.037 & 0.035 \\
\hline
\end{tabular}

+Included populations $1,2,3,4,6,7,8,9,10,11,12,15,16,17,18$, $19,20,21$ and 22.

‡Included populations 5, 13, 14, 23, 24, 25, 26, 27, 28, 29 and 30. *Indicated significantly different from zero at the $P<0.05$ level. Values in parenthesis are standard deviation.

$\left.0.496, H_{\mathrm{S}}=0.082\right)$ exhibited greater differentiation and total diversity than populations in western Taiwan $\left(G_{\mathrm{ST}}=0.644\right.$, $\left.H_{\mathrm{T}}=0.413, H_{\mathrm{S}}=0.147\right)$. The values of $N_{\mathrm{ST}}-G_{\mathrm{ST}}$ east and west of the CMR were not significantly different from zero.

Genetic population differentiation in the pairwise comparison was analysed by AMOVA, pairwise $F_{\mathrm{ST}}$ values indicated that most population pairs significantly differed (not shown). Interestingly, through calculation of average $F_{\mathrm{ST}}$ values for individual C. carlesii populations in comparison to every other population, we found that LS and HK were genetically the most-distinct populations, followed by JS, LY, MF and PT.

Populations LH, AM, TC and FS contributed most to the diversity component of the total diversity (Fig. 4) due to their high haplotype diversity, while populations HK, LY, JS, MF and PT contributed most to the differentiation component of the total diversity. The contributions were due to specific rare alleles in each population that were frequent in those populations, resulting in a high contribution to differentiation. As to the contribution to allelic richness, populations LY, HK, PT and MF contributed most to the differentiation component (not shown). So the same populations contributed most to the total diversity and allelic richness.

\section{Correlation between genetic distance and geographical distance}

The MEGA program was used to calculate the genetic distance between populations. Genetic distances between populations ranged from 0 to 0.0035 , with an average of 0.00095 (data not shown). No correlation was found between geographical distance and genetic distance checked by Mantel tests (data not shown). From the genetic distance matrix, it is very interesting to note that the highest distance was between HK and JS, 0.0035 . These two populations are 


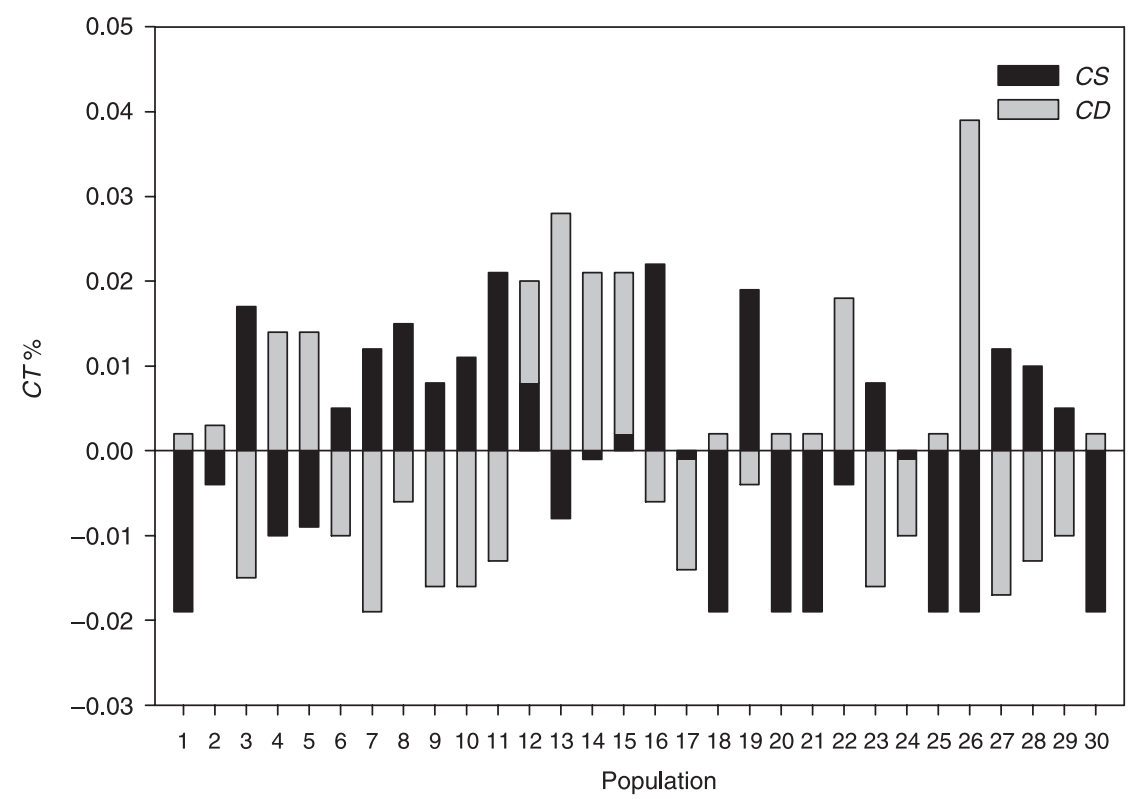

Fig. 4 Contribution to the total diversity $(C T)$ of each population of Castanopsis carlesii for chloroplast haplotypes. Grey bars and closed bars represented contribution of differentiation and diversity, respectively. Numbers corresponding to populations are given in Table 1. located in eastern Taiwan, with a geographical distance between them of less than $60 \mathrm{~km}$. HK also had high levels of genetic distance with other populations, LY, at 0.0032, and $\mathrm{LH}$, at 0.0030 . The genetic distance between LY and MF was also high (0.0033).

\section{Discussion}

\section{Nucleotide diversity of cpDNA}

Because of the maternal inheritance and low rate of mutation, noncoding regions of $\mathrm{cpDNA}$, i.e. intergenic spacer (IGS) and intron, are suitable markers for analysis of evolutionary processes at lower taxonomic level (Soltis \& Soltis 1998). Due to different mutation rates, combining noncoding regions to obtain more variable characters or informative sites was necessary. In this study, we selected and combined two noncoding regions, one intron ( $\operatorname{trn} \mathrm{L}$ ) and one IGS (trnV-trn M), in order to investigate the genetic variation. The mutational rate of the $t r n \mathrm{~L}$ intron is faster than that of the $\operatorname{trn} \mathrm{V}-t r n \mathrm{M}$ spacer. When compared with other species that occur in Taiwan, the nucleotide diversity of Castanopsis carlesii (0.00095) was greater than Castanopsis glauca ( $\pi=0.00065$, from a combination of $\operatorname{trn} \mathrm{T}-\operatorname{trn} \mathrm{L}, \operatorname{trn} \mathrm{V}$ trn $\mathrm{M}$ and petG-trnP) (Huang et al. 2002), Cunninghamia konishii ( $\pi=0.00190$, from a combination of $t r n \mathrm{~V}$ intron, trn D-trn T, trn L-trnF and petG-trnP) (Hwang et al. 2003) and Trochodendron aralioides ( $\pi=0.00052$, from a combination of petG-trnP and petA-psbJ) (Huang et al. 2004). The level of nucleotide diversity from 0.00050 to 0.00200 appeared to be the range for the intraspecific level found in Taiwan, and is slightly higher than that reported from other species.
Range expansion after the glacial period and the population founder effect in central Taiwan

The present distribution of haplotypes reflects recolonization events after the glacial period. The distribution of the numbers of pairwise nucleotide differences is affected by the demographic history. Mismatch analysis showing a unimodal distribution and significant Tajima's $D$ neutrality test, indicated a recent population expansion. From the TCS analysis, genetic genealogies were stretched near the external nodes and compressed near the root, and the haplotype relationship appearing 'star-like', and originating from the ancestral haplotypes, 1 and 2, also support a result of range expansion. Range expansion would have begun from the refuge. The CMR extends from north to south with more than 100 mountain peaks over $3000 \mathrm{~m}$. The different haplotypes distributed on both sides of the CMR support that the CMR formed a geographical barrier to bidirectional east-west gene flow. A similar effect also has been observed in the study of C. glauca (Huang et al. 2002) and animal species, such as the rice frog, Rana limnocharis (Toda et al. 1998), and tree squirrel, Callosciurus erythraeus (Lee 2003).

It is very interesting to note that no ancestral type was found in MF and LS, two central Taiwan populations, nor in three eastern populations, JS, LY and HK. A similar result was also observed in the study of C. glauca (Huang et al. 2002). Genetic drift might possibly explain the elimination of the ancestral haplotypes during the colonization course. But this event required a strong drift effect; it is unlikely to occur in a dominant tree species producing many seeds. We propose that this distribution pattern is the result of a founder effect; a new colonizer established a population and inhibited the establishment of later arrivals 
through niche preemption or intraspecific competition (Silvertown 2004).

We have found that the differences of $N_{\mathrm{ST}}-G_{\mathrm{ST}}$ for populations on both western and eastern CMR are not significant. Thus the inference of a pool of haplotypes must have exited during glaciaton and today's distribution patterns are greatly influenced from their original frequencies and the cpDNA gene pools of refugium. The presence of a phylogeographical structure, however, as total populations being considered together indicates that closely related haplotypes were more often found in the same area than less closely related haplotypes (Pons \& Petit 1996). This might be caused by the effect of mixing from different refugia.

\section{Two potential refugia recognized in Taiwan}

Gene genealogies could be used to trace the phylogenetic relationships of the geographical distribution of haplotypes. Interior positions coupled with the high frequency indicated that the ancestral types were haplotypes 1 and 2 . According to the coalescent theory, these haplotypes would have a great probability of producing mutational derivatives and may represent some relict ancestral genotypes (Crandall \& Templeton 1993). After the postglacial recolonization, the ancestral haplotypes were widespread, and it would have been hard to trace the sites of glacial refugia. The derived or unique haplotypes help to identify refuge. In our study, the northern Taiwan populations, including FS, KW, CH, owned six unique or rare haplotypes among the eight types. Haplotype 3, an important type derived from haplotype 1 , had a higher frequency in the $\mathrm{CH}$ population, and many haplotypes $(4,5,6,7$ and 28) evolved from it. According to haplotype phylogeny and frequency of rare haplotypes, $\mathrm{CH}$ might have been the source of populations LS, MF and LH. These three populations contained haplotypes $4,5,6,7$ and 28, which hint at a clear recolonization route. We propose that the region covering populations $\mathrm{FS}, \mathrm{KW}, \mathrm{CH}$, LS and $\mathrm{MF}$ (elevations from 600 to $2200 \mathrm{~m}$ ), especially the first three sites would be the first refugium in Taiwan. This refugium is located in the northern part of Hsuehshan Range. Interestingly, this location conforms to the only potential refugium site for T. aralioides (Huang et al. 2004) and C. konishii (Chung et al. 2004) both of which are temperate tree species.

Populations in southeastern Taiwan, i.e. LC, LM and JS, contained nine haplotypes, among which seven were unique. To consider the haplotype uniqueness and nucleotide diversity, we propose that the region covering populations LC, LM, HK, JS and LY (elevations from 500 to $1400 \mathrm{~m}$ ) was a potential second refuge of C. carlesii in Taiwan. In addition, this location coincides with the only potential refuge site for Quercus glauca, a subtropical tree species (Huang et al. 2002). Moreover, populations HK, LY, JS, and PT have the highest contributions to the differentiation component of the total diversity (Fig. 4) and allelic richness. This also supports the importance of south Taiwan, especially southeastern part in the pooling of many rare private alleles. Why many unique chlorotypes observed in the two mountain refugia never extended to lower elevations, with exception of the two ancestral ones (Nos 1 and 2)? The occurrence of unique haplotypes may be attributable to the geographical isolation of very small populations in the specific conditions observed in the mountain where the species may have settled after the glaciations. Isolation probably favoured the fixation of several successive mutations.

However, we are not clear why in the Last Glacial Maximum (LGM) the refugia were located in such high altitudes. One of the explanations is related to a dry environment that prevailed in Taiwan 20000 years BP that was indicated by a remarkably high value of herbs (Poaceae) (Liew \& Chung 2001). Furthermore, it has been documented that the interglacial became more warm and wet compared to glacial due to the intensification of summer monsoons (Huang et al. 1997). Therefore, lower temperature together with drier environment may have forced species like C. carlesii to retreat into some refugia during glacial and subsequently expanded to its present distributions.

It was found that in the common ivy in Europe, differentiation of each population from the remaining ones revealed a latitudinal pattern, with populations from the south being significantly more differentiated from the pooled remaining populations than the central or northern populations (Grivet \& Petit 2002). Thus population divergence or genetic differentiation can be useful criteria for locating the region of glacial refugium. Petit et al. (2003) tested the hypothesis that glacial refuge areas harbour a large fraction of intraspecific diversity. They concluded that plant populations in refugial areas had high genetic divergence and uniqueness rather than a high number of haplotypes. The concept of genetically highly divergent populations existing in regions of glacial refugium is also supported in the common ash (Heuertz et al. 2004). The average $F_{\mathrm{ST}}$ for individual C. carlesii populations in comparison with the remaining populations signified the most-divergent populations were located at LS and HK, followed by JS, LY, MF and PT. Populations LY, JS, HK and PT coincide with the second refugium described above, and populations LS and $\mathrm{MF}$ are at lower range of the first refugium.

The present genetic structure and level of genetic diversity can be associated with historical events. Different ecological and habitat requirements result in different phylogeographical patterns when populations experience tremendous climate changes. As a subtropical to warmtemperate species, C. carlesii being found in wide-ranging habitats made it possible to survive in these two refugia when the climate changed, and to recolonize from the refugia when the climate again became warmer. 
An area showing higher levels of genetic diversity might be caused by two effects: a refuge which is an area with a stable ecological habitat during environmental fluctuations fostering the accumulation of genetic diversity (Tzedakis et al. 2002); or an intermediate zone that receives an admixture of organisms from different sources, resulting in higher genetic diversity than the original sources (Petit et al. 2003). Three populations exhibiting high nucleotide diversity of cpDNA of $C$. carlesii, i.e. FS $(\pi=0.00116)$, LH $(\pi=0.00136)$ and LC $(\pi=0.00091)$ are located in northern, central and southeastern Taiwan, respectively. The LH population had the highest levels of nucleotide and haplotype diversity. Pollen records from the Toushe peat pog, in central Taiwan (near LH), in the LGM, about 20000 years $\mathrm{BP}$, were dominated by a high percentage of herbs, and forest elements such as Quercus. Pollen of Castanopsis remarkably increased at the Holocene/Pleistocene transition (Kuo \& Liew 2000). Tsukada (1967) also suggested that the temperature during the LGM, 70000 years BP, was $8-11^{\circ} \mathrm{C}$ cooler than today in central Taiwan and that low elevations were dominated by conifers. Thus we do not favour the LH area as the potential refugium because environment in this area was considered not to be favourable to C. carlesii during the LGM. We suggest that the higher diversity in the LH population and nearby areas resulted from an admixture of the diversity of two colonization routes from north and south after the glacial. The reason why the region of FS has higher diversity is unclear.

The diversity centre and haplotype geographical structure found in C. carlesii were similar to those of C. glauca (Huang et al. 2002). Three populations, Yangmingshan (northern Taiwan close to FS), Wushe (central Taiwan close to LH) and Tahanshan (southern Taiwan close to LC) of C. glauca showed higher haplotype diversity than other populations. Although these three populations were not matched completely in these two studies, the opponent populations were geographically correlated.

\section{Acknowledgements}

This study was supported by the Taiwan Forestry Research Institute (contribution no. 300), and the National Science Council (grant numbers NSC93-2313-B-002-037), Executive Yuan, Taiwan.

\section{References}

Avise JC (2000) Phylogeography: The History and Formation of Species. Harvard University Press, Cambridge, Massachusetts.

Bennett KD (1990) Milanokovitch cycles and their effects on species in ecological and evolutionary time. Paleobiology, 16, 11-21.

Brewer S, Cheddadi R, de Beaulieu JL, Reille M, Data contributors (2002) The spread of deciduous Quercus throughout Europe since the last glacial period. Forest Ecology and Management, 156, $27-48$.

Chung JD, Lin TP, Tan YC, Lin MY, Hwang SY (2004) Genetic diversity and biogeography of Cunninghamia konishii (Cupressaceae), an island species in Taiwan: a comparison with Cunninghamia lanceolata, a mainland species in China. Molecular Phylogeny and Evolution, 33, 791-801.

Clegg MT, Zurawski G (1992) Chloroplast DNA and the study of plant phylogeny: present status and future prospects. In: Molecular Systematics of Plants (eds Soltis PS, Soltis DE, Doyle JJ), pp. 1-13. Chapman \& Hall, New York.

Corriveau JL, Coleman AW (1988) Rapid screening method to detect potential biparental inheritance of plastid DNA and results for over 200 angiosperm species. American Journal of Botany, 75, 1443-14458.

Crandall KA, Templeton AR (1993) Empirical tests of some predictions from coalescent theory with applications of to intraspecific phylogeny reconstructure. Genetics, 134, 959-969.

Csaikl UM, Burg K, Fineschi S, Konig AO, Matyas G, Petit RJ (2002) Chloroplast DNA variation of white oaks in the Alpine region. Forest Ecology and Management, 156, 131-145.

Demesure B, Comps B, Petit RJ (1996) Chloroplast phylogeography of the common beech (Fagus sylvatica L.) in Europe. Evolution, 50, 2512-2520.

Dumolin-Lapegue S, Demesure B, Fineschi S, Lecorre V, Petit RJ (1997) Phylogeographic structure of white oaks throughout the European continent. Genetics, 146, 1475-1487.

Ferris C, King RA, Vainola R, Hewitt GM (1998) Chloroplast DNA recognizes three refugial sources of European oaks and suggests independent eastern and western immigrations to Finland. Heredity, 80, 584-593.

Grivet D, Petit RJ (2002) Phylogeography of the common ivy (Hedera sp.) in Europe: genetic differentiation through space and time. Molecular Ecology, 11, 1351-1362.

Hare MP (2001) Prospects for nuclear gene phylogeography. Trends in Ecology \& Evolution, 16, 700-706.

Harpending H (1994) Signature of ancient population growth in a low resolution mitochondrial DNA mismatch distribution. Human Biology, 66, 591-600.

Heuertz M, Hausman JF, Hardy OJ, Vendramin GG, FrascariaLacoste N, Vekemans X (2004) Nuclear microsatellites reveal contrasting patterns of genetic structure between western and southern European populations of the common ash (Fraxinus excelsior L.). Evolution, 58, 976-988.

Hewitt G (2000) The genetic legacy of the Quaternary ice ages. Nature, 405, 907-913.

Hiramatsu M, Ii K, Okubo H, Huang KL, Huang CW (2001) Biogeography and origin of Lilium longiflorum and L. formosanum (Liliaceae) endemic to the Ryukyu Archipelago and Taiwan as determined by allozyme diversity. American Journal of Botany, 88, 1230-1239.

Hsieh CF, Shen CF, Yang KC (1994) Introduction to the flora of Taiwan 3. Floristics, phytogeography, and vegetation. In: Flora of Taiwan, Vol. 1 (ed. Editorial Committee of Flora of Taiwan), 2nd edn, pp. 7-18. Editorial Committee of the Flora of Taiwan, Taipei, Taiwan.

Huang CY, Liew PM, Zhao M et al. (1997) Deep sea and lake records of the Southeast Asian paleomonsoons for the last 25 thousand years. Earth and Planetary Science Letters, 146, $59-72$.

Huang SSF, Hwang SY, Lin TP (2002) Spatial pattern of chloroplast DNA variation of Cyclobalanopsis glauca in Taiwan and East Asia. Molecular Ecology, 11, 2349-2358.

Huang SF, Hwang SY, Wang JC, Lin TP (2004) Phylogeography of Trochodendron aralioides (Trochodendraceae) in Taiwan and its adjacent areas. Journal of Biogeography, 31, 1291-1239. 
Hwang SH, Lin TP, Ma CS, Lin CL, Chung JD, Yang JC (2003) Postglacial population growth of Cunninghamia konishii (Cupressaceae) inferred from phylogeographical and mismatch analysis of chloroplast DNA variation. Molecular Ecology, 12, 2689-2695.

Kimura M (1980) A simple method for estimating evolutionary rates of base substitutions through comparative studies of nucleotide sequences. Journal of Molecular Evolution, 10, 111-120.

Kumar S, Tamura K, Jakobsen IB, Nei M (2001) MEGA2: molecular evolutionary genetics analysis software. Bioinformatics, 17, 1244-1245.

Kuo CM, Liew PM (2000) Vegetational history and climatic fluctuations based on pollen analysis of the Toushe peat bog, central Taiwan since the Last Glacial Maximum. Journal of the Geological Society of China, 43, 379-392.

Lee JK (2003) Phylogeography of the red-bellied tree squirrel Callosciurus erythraeus of Taiwan and reexamination of its subspecific status. Tunghai University, Master's Thesis. (in Chinese with English summary).

Li WH (1997) Molecular Evolution. Sinauer Associates, Sunderland, Massachusetts.

Liao JC (1996) Fagaceae. In: Flora of Taiwan, Vol. 2 (ed. Editorial Committee of Flora of Taiwan), 2nd edn, pp. 51-123. Editorial Committee of the Flora of Taiwan, Taipei, Taiwan.

Liew PM, Chung NJ (2001) Vertical migration of forests during the last glacial period in subtropical Taiwan. Western Pacific Earth Science, 1, 405-414.

Lin TP (2001) Allozyme variations in Michelia formosana (Kanehira) Masamune (Magnoliaceae), and the inference of glacial refugium in Taiwan. Theoretical and Applied Genetics, 102, 450-457.

Matyas G, Sperisen C (2001) Chloroplast DNA polymorphism provide evidence for postglacial re-colonisation of oaks (Quercus spp.) across the Swiss Alps. Theoretical and Applied Genetics, 102, 198-202.

Petit RJ, Kremar A, Wagner DB (1993) Finite island model for organelle and nuclear genes in plants. Heredity, 71, 630-641.

Petit RJ, Pineau E, Demesure B, Bacilieri R, Ducousso A (1997) Chloroplast DNA footprints of post glacial recolonization by oaks. Proceedings of the National Academy of Sciences of the United States of America, 94, 9996-10001.

Petit RJ, El Mousadik A, Pons O (1998) Identifying populations for conservation on the basis of genetic marker. Conservation Biology, 12, 844-855.

Petit RJ, Aguinagalde I, De Beaulieu JL et al. (2003) Glacial refugia: hotspots but not melting pots of genetic diversity. Science, 300 , 1563-1565.

Pons O, Petit RJ (1995) Estimation, variance and optimal sampling of gene diversity. I. Haploid locus. Theoretical and Applied Genetics, 90, 462-470.

Pons O, Petit RJ (1996) Measuring and testing genetic differentiation with ordered versus unordered alleles. Genetics, 144, 1237-1245.

Richardson BA, Brunsfeld SJ, Klopfenstein NB (2002) DNA from bird-dispersed seed and wind-disseminated pollen provides insights into postglacial colonization and population genetic structure of whitebark pine (Pinus albicaulis). Molecular Ecology, 11, 215-227.

Rogers AR, Harpending H (1992) Population growth makes waves in the distribution of pairwise genetic difference. Molecular Biology and Evolution, 9, 552-569.

Rozas J, Rozas R (1999) DNAsP, version 3: an integrated program for molecular population genetics and molecular evolution analysis. Bioinformatics Application Note, 15, 174-175.

Schneider S, Roessli D, Excoffier L (2000) ARLEQUIN, Version 2.000: a software for population genetic data analysis. Genetics and Biometry Laboratory, Department of Anthropology, University of Geneva, Switzerland.

Shen CF (1994) Introduction to the flora of Taiwan, 2: geotectonic evolution, paleogeography, and the origin of the flora. In: Flora of Taiwan. Vol. 1 (ed. Editorial Committee of the Flora of Taiwan), 2nd edn, pp. 3-7. Editorial Committee of the Flora of Taiwan, Taipei, Taiwan.

Shen CF (1997) The Biogeography of Taiwan: 2. Some preliminary thoughts and studies. Annual Report of Taiwan Museum, 40, 361450. (in Chinese with English summary).

Silvertown J (2004) The ghost of competition past in the phylogeny of island endemic plants. Journal of Ecology, 92, 168-173.

Soltis DE, Soltis PS (1998) Choosing an approach and appropriate gene for phylogenetic analysis. In: Molecular Systematics of Plant II: DNA Sequencing (eds Soltis DE, Doyle JJ), pp. 1-42. Kluwer Academic, Norwell, Massachusetts.

Taberlet P, Fumagalli L, Wust-Saucy AG, Cossons JF (1998) Comparative phylogeography and postglacial colonization routes in European. Molecular Ecology, 7, 453-464.

Templeton AR, Crandall KA, Sing CF (1992) A cladistic analysis of phenotypic associations with haplotypes inferred from restriction endonuclease mapping and DNA sequence data. III. Cladogram estimation. Genetics, 132, 619-633.

Thompson JD, Higgins DG, Gibon TJ (1994) CLustal w: improving the sensitivity of progressive multiple sequence alignment through sequence weighting, position-specific gap penalties and weight matrix choice. Nuclear Acids Research, 22, 4673-4680.

Toda M, Nishida M, Matsui M, Lue KY, Ota H (1998) Genetic variation among populations of the Indian rice frog, Rana limnocharis (Amphibia: Anura) within Taiwan: revealed by allozyme data. Herpetologoca, 54, 78-82.

Tsukada M (1966) Late Pleistocene vegetation and climate in Taiwan (Formosa). Proceedings of National Academy of Sciences of the United States of America, 55, 543-584.

Tsukada M (1967) Vegetation in subtropical Formosa during the Pleistocene glaciations and the Holocene. Palaeogeography, Palaeoclimatology, Palaeoecology, 3, 49-64.

Tzedakis PC, Lawson IT, Forgley MR, Hewitt GM (2002) Buffered tree population changes in Quaternary refugium: evolutionary implication. Science, 292, 267-269.

Wolfe KH, Li WH, Sharp PM (1987) Rates of nucleotide substitution vary greatly among plant mitochondria, chloroplast, and nuclear DNAs. Proceedings of the National Academy of Sciences of the United States of America, 84, 9054-9058.

Wright S (1931) Evolution in Mendelian populations. Genetics, 16, 97-159.

Xia X, Xie Z (2001) DAMBE: data analysis in molecular biology and evolution. Journal of Heredity, 92, 371-373.

Yu-Pin Cheng currently a graduate student in the Institute of Plant Biology, Taiwan University, has research interests in population genetics and molecular systematics of forest trees. He has a permanent position in Taiwan Forestry Research Institute, Division of Forest Biology. Shih-Ying Hwang is a Professor in the Graduate Institute of Biotechnology, Chinese Culture University, with research interests in the evolutionary genetics of plant species that are native to Taiwan. Tsan-Piao Lin is a Professor in the Institute of Plant Biology, National Taiwan University with research interests in the phylogeography and plant stress biology. 